\title{
Anion Recognition by Charge Neutral Electron-deficient Arene Receptors
}

\author{
De-Xian Wang*a and Mei-Xiang Wang ${ }^{* a b}$
}

\begin{abstract}
Anion- $\pi$ interactions are newly emerging non-covalent interactions and have attracted considerable attention from both theoreticians and supramolecular chemists. This short review article summarizes the recent advances in anion recognition using charge neutral electron-deficient aromatic compounds.
\end{abstract}

Keywords: Anion- $\pi$ interactions · Anion recognition · Charge neutral electron-deficient arenes . Synthetic receptors

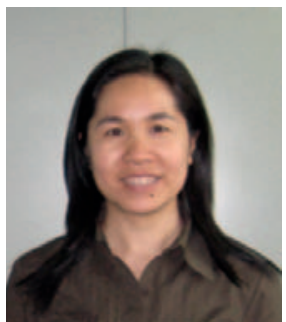

De-Xian Wang is a Professor at the Institute of Chemistry, Chinese Academy of Sciences in Beijing. She works in the field of supramolecular chemistry with research interests focusing on molecular recognition and self-assembly. Currently she is particularly interested in anion recognition based on non-covalent bond interactions between anions and electrondeficient arenes.

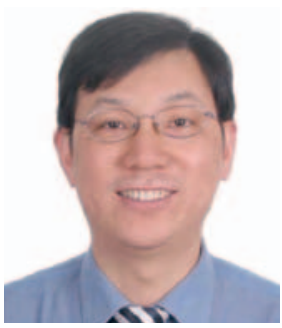

Mei-Xiang Wang is a Professor of Organic Chemistry at Department of Chemistry, Tsinghua University in Beijing. He worked at the Institute of Chemistry, Chinese Academy of Sciences before 2009. His research interests include supramolecular chemistry of novel and functional macrocyclic molecules,

\footnotetext{
${ }^{\star}$ Correspondence: Prof. D.-X. Wanga; Prof. M.-X. Wangab

aBeijing National Laboratory for Molecular Sciences CAS Key Laboratory of Molecular Recognition and Function

Institute of Chemistry, Chinese Academy of Sciences Beijing 100190, China.

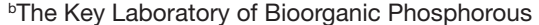
Chemistry \& Chemical Biology (Ministry of Education) Department of Chemistry, Tsinghua University Beijing 100084, China.

E-mail: dxwang@iccas.ac.cn; wangmx@mail.tsinghua edu.cn
}

enantioselective biocatalysis and biotransformations, and organic reactions and their applications in the synthesis of natural and bioactive products.

\section{Introduction}

The recognition of anions is a challenging topic in supramolecular chemistry.[1,2] A majority of synthetic receptors for anions have been designed based on electrostatic attraction, ${ }^{[3]}$ hydrogen bonding ${ }^{[4]}$ and Lewis acid-base interaction. ${ }^{[5]}$ In 2002, Mascal, Deyà, and Alkorta published almost simultaneously their independent theoretical studies on the non-covalent interaction between anions and electron-deficient aromatics such as triazine, hexafluorobenzene and perfluoroaromatic compounds. ${ }^{[6-8]} \mathrm{A}$ rapid development of the investigation of anion- $\pi$ interactions has been witnessed ever since. Various computational studies have been conducted and experimental evidence of anion- $\pi$ interactions both in the solid state and in solution has been reported. This review summarizes the recent advances in the study of anion recognition utilizing charge neutral electron-deficient arene receptors. Studies of anion- $\pi$ interactions with charged and metal-coordinated electron deficient aromatic rings are not included in this article and readers are referred to recent review articles. ${ }^{[9-11]}$

\section{Theoretical Studies of Anion- $\pi$ Interactions}

It is well known that benzene possesses negative electrostatic potential on the aromatic ring, and it is able to act as an electron donor to interact with electrondeficient and positively charged species (cation- $\pi$ interaction) and hydrogen $(\mathrm{CH}-\pi$ interaction). Interaction of the benzene ring with electron-rich species is regarded to be disfavored thermodynamically. Alkorta's calculations in 1997, however, suggested the favorable interaction of hexafluorobenzene, an electron-deficient aromatic ring, with several electron-donating small molecules such as $\mathrm{HF}, \mathrm{LiH}$ and $\mathrm{HCN} .{ }^{[12]}$ Two years later, Dougherty reported $a b$ initio molecular orbital calculations, illustrating that water is able to associate with hexafluorobenzene through lone pair electron- $\pi$ interaction with the binding energy being in the range of 1.5-4 kcal/ mol depending on the calculation methods utilized. ${ }^{[13]}$ Inspired by the results of lone pair electron- $\pi$ interaction, Mascal in 2002 reported a MP2/6-31+G* method for the theoretical study of interaction of 1,3,5-triazine and trifluoro-1,3,5-triazine with anions including fluoride, chloride and azide. [6] They showed for the first time a noncovalent binding mode between an anion and the centroid of an electron-deficient aromatic ring. In addition, minima for both $\mathrm{C}-\mathrm{H}^{\cdots} \mathrm{X}^{-}$hydrogen bonding and formation of reactive complexes derived from nucleophilic attack on the triazine ring were also predicted. ${ }^{[4]}$ Deyà and coworkers conducted theoretical calculations at $\mathrm{HF} / 6$ $31++\mathrm{G}^{* *}$ and MP2/6-31++G** levels to demonstrate the energetically favored anion- $\pi$ interaction. ${ }^{[7]}$ By using Molecular Interaction Potential with Polarization (MIPp), they pointed out that the main contributions to anion- $\pi$ interaction are electrostatic and polarization components. Almost at the same time, Alkorta et al. published their DFT (B3LYP/6-31++G**) and MP2 (MP2/6-31++G** and MP2/6$311++\mathrm{G}^{* *}$ ) ab initio methods to evaluate the interaction of anions with perfluorobenzene compounds. ${ }^{[8]}$ The minima for the complexes between anions and the $\pi$-cloud of the perfluoroaromatic derivatives were obtained with stabilization energy ranging from $-8 \mathrm{kcal} / \mathrm{mol}$ to $-19 \mathrm{kcal} /$ mol. Following these pioneering studies, 
many types of aromatic compounds have been employed as electron-deficient components to verify theoretically the non-covalent anion- $\pi$ interactions. ${ }^{[14-24]}$ It is very interesting to note that although anion- $\pi$ interaction predicted by most of the calculations is attributed to the electrostatic and polarization effects, different opinions have also appeared in literature. ${ }^{[14,15]} \mathrm{Kim}$ and coworkers, for example, have carried out high level $a b$ initio calculations and used symmetry adapted perturbational theory (SAPT) method to investigate the nature of anion- $\pi$ interactions. Except for electrostatic and induction energies, they suggest that the contribution from dispersion energy is substantial for anion- $\pi$ interaction. ${ }^{[14]}$ Being different from most of the theoretical studies in which the typical noncovalent anion- $\pi$ interaction mode, viz. the interaction of anion with the centroid of electron-deficient aromatics is focused, Hay and his coworkers have shown varied anion- $\pi$ interaction motifs based on their theoretical and experimental studies. ${ }^{[15]}$ On the basis of MP2/aug-cc-pVDZ calculations of the interactions of $\mathrm{F}^{-}, \mathrm{Cl}^{-}$and $\mathrm{Br}$ with 1,2,4,5-tetracyanobenzene (TCB), 1,3,5-tricyanobenzene, triazine and hexafluorobenzene, they have proposed three distinct types of complexes. As depicted in Fig. 1, in addition to the typical non-covalent anion- $\pi$ complex $A$, both weak and strong $\sigma$-type donor- $\pi$-acceptor complexes $\mathrm{B}$ and $\mathrm{C}$ are also energetically favored. Noticeably, they also emphasize that if aryl $\mathrm{C}-\mathrm{H}$ is present in electron-deficient arenes, the $\mathrm{C}-\mathrm{H} \cdots \mathrm{X}^{-}$hydrogen bonding motif $\mathrm{D}$ becomes an energetically more favorable interaction. A survey of the complexes in Cambridge Structural Database along with their own study on the X-ray single crystal structure of anion-TCB complexes led them to conclude that authentic examples of typical anion- $\pi$ interaction as motif A are very rare, and weak $\sigma$-type anion- $\pi$ interaction as motif $\mathrm{B}$ is predominant.

\section{Anion- $\pi$ Interactions in the Solid State}

Since the publications of theoretical studies on anion- $\pi$ interactions, increasing numbers of examples of interactions between anions and electron-deficient systems have emerged.[15,25-29] Among these published examples, recognition of anions by charge neutral organic molecules is unique and noteworthy. Excluding the charge-charge attraction and Lewis acid-base interaction, electron-deficient charge neutral organic molecules provide excellent platforms for anion interactions, enabling the unambiguous elucidation of the nature of anion- $\pi$ interactions.

In 2004, Kochi and coworkers reported
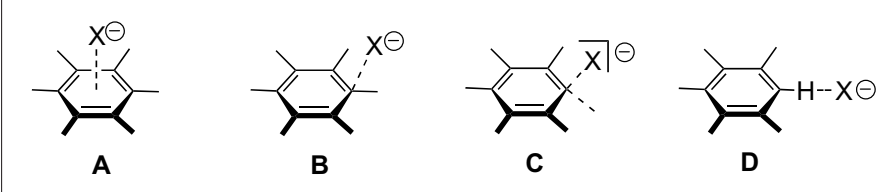

Fig. 1. Different anion- $\pi$ interaction motifs proposed by Hay and coworkers.

their study of the interaction between anions and a series of neutral organic $\pi$ receptors such as TCB, 1,3,5-trinitrobenzene (TNB), 2,3,5,6-tetracyanopyrazine (TCP), 2,3,5,6-tetrachlorocyclohexa-2,5-diene1,4-dione (p-CA), 3,4,5,6-tetrachlorocyclohexa-3,5-diene-1,2-dione (o-CA) and 1,1,2,2-tetracyanoethene (TCNE). ${ }^{[25]}$ From the crystal structure of the complexes of halides with TCP (Fig. 2a) and TCNE, halides are found to contact with carbon atoms of the $\pi$ receptors with the distance of $\mathrm{C}^{\cdots} \mathrm{X}^{-}$shorter than the sum of their van der Waals radii, indicating clearly a weak $\sigma$-type anion- $\pi$ interaction motif B (Fig. $2 b)$. The same group has also examined the interaction between other anions such as thiocyanate, nitrite/nitrate, sulfite/sulfate and tetrahalometallate and the neutral $\pi$ acids aforementioned, showing that the anion- $\pi$ interaction leads to the formation of self-assembled linear 1D wires (Fig. 2c). ${ }^{[26]}$ Using TCB as a building block, Hay and coworkers observed $\mathrm{C}^{\cdots} \mathrm{X}^{-}$and $\mathrm{C}-\mathrm{H} \cdots \mathrm{X}^{-}$ hydrogen bond interactions in the complex of TCB with bromide and iodide.[15] A recent report by Dunbar and coworkers shows a remarkable $1 \mathrm{D}$ vertical ABCD self-assembly through multiple anion- $\pi$ interactions. ${ }^{[27]}$ It is very interesting to note that symmetric hexaazatriphenylenehexacarbonitrile $\mathrm{HAT}(\mathrm{CN})_{6}$ acts as a dual electron-deficient aromatic component to interact with halides. Significantly, while one halide forms typical anion- $\pi$ interactions with the centroid of a large $\pi$-system on one side, three halides contact the molecule on the other side via multisite $\eta^{2}, \eta^{2}$-type interactions (Fig. 3).

The first example of typical non-covalent anion- $\pi$ interaction formed by anions and charge neutral $\pi$-deficient arenes was reported by us in 2008. ${ }^{[28]}$ Heteroatom bridged calix(hetero)aromatics are an emerging type of novel macrocyclic host molecule in supramolecular chemistry. ${ }^{[30-33]} \mathrm{Be}-$ cause of the different electronic nature of heteroatoms from carbon, the heteroatombridged calix(hetero)aromatics exhibit interesting structural and molecular recognition properties in contrast to conventional calixarenes. As one of the typical examples of heteroatom bridged calix(hetero)aromatics, tetraoxacalix[2] arene[2]triazines have been reported to adopt a pre-organized 1,3-alternate conformation, yielding a V-shaped cleft formed by two $\pi$-electron deficient triazine rings. ${ }^{[34]}$ The electron-deficient cavity renders tetraoxacalix[2]arene[2]triazines

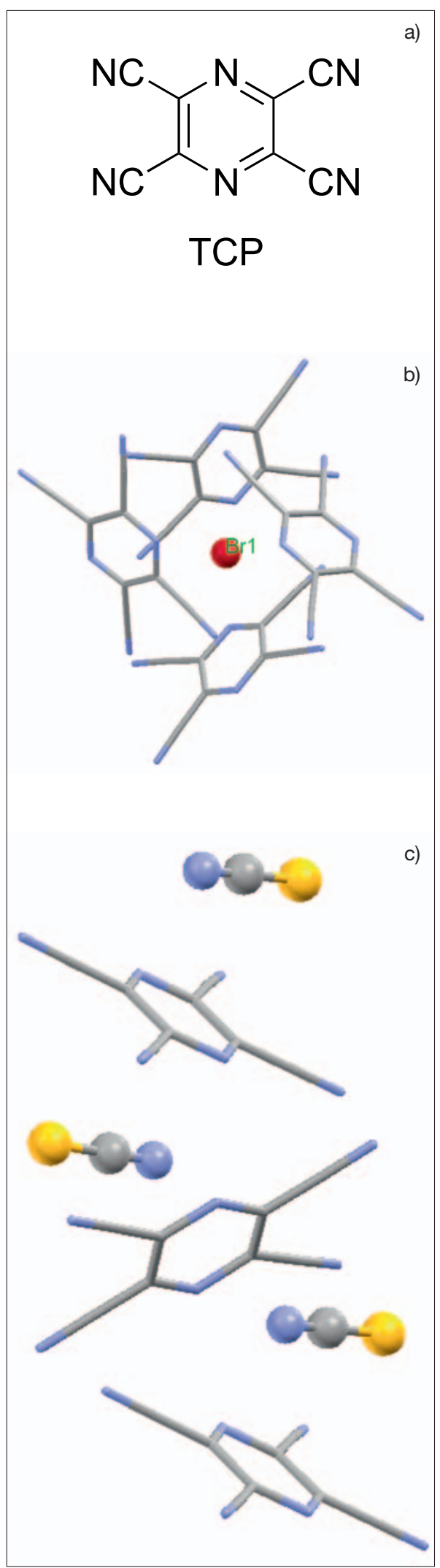

Fig. 2. Structure of TCP (a), complex between TCPs and bromide (b), and the linear 1D wire self-assembled from anion- $\pi$ interactions between TCP and thiocyanate (c). 


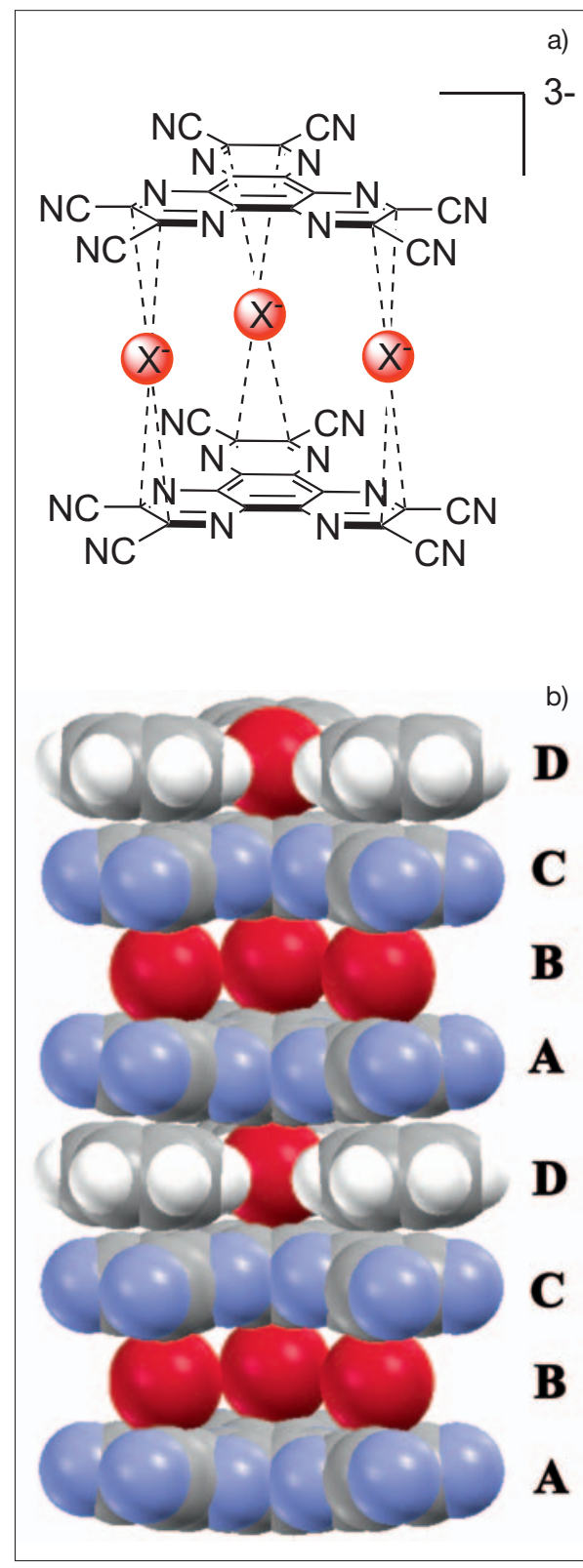

Fig. 3. Multiple anion- $\pi$ interactions (a) and $1 D$ vertical $A B C D$ self-assembly between $\operatorname{HAT}(\mathrm{CN})_{6}$ and halides (b).

(Fig. 4, left) unique macrocyclic hosts for the recognition of anions. As unveiled by X-ray crystallography (Fig. 4), dichlorosubstituted tetraoxacalix[2] arene[2] triazine $\mathbf{1}$ forms ternary complexes with a halide and a water molecule in the solid state. The included chloride or bromide locates almost over the center of one of the triazine rings, with a vertical distance to the triazine plane being 3.218-3.247 $\AA\left(d_{\text {Cl-plane }}\right)$ or 3.273-3.348 $\AA \quad\left(d_{\text {Br-plane }}\right)$, respectively. The short distance of halide to the triazine centroid indicates convincingly a typical non-covalent anion- $\pi$ interaction. Concurrently, the water molecule, which is hydrogen-bonded to halide as evidenced by the oxygen-halide distance of 3.214-3.233 $\AA$, forms a $\mathrm{H}_{2} \mathrm{O}-\pi$ (lone-pair electron- $\pi$ ) interaction with the other triazine ring. This is supported by the short distance between
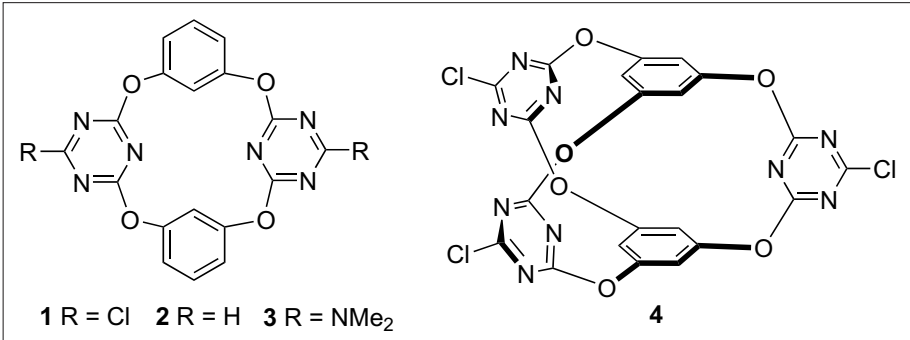

Fig. 4. Structure of substituted tetraoxacalix[2] arene[2] triazines 1-3 and bis(tetraoxacalix[2] arene[2]triazine) 4. the chloride is also hydrogen-bonded to the accommodated water molecule $\left(d_{\mathrm{Cl}(2)-\mathrm{O}(3)}=\right.$ $3.163 \AA$ ), and the later is further interacted by arene $\mathrm{C}-\mathrm{H}$ of the other benzene ring through hydrogen bonding $\left(d_{\mathrm{O}(3)-\mathrm{C}(7)}\right.$ $=3.065 \AA$ ) (Fig. 6, left). To complex bromide, however, host molecule 4 selfregulates its conformational structure yielding three $\mathrm{V}$-shaped clefts of different sizes $\left(d_{G l-C l}=11.955 \AA, 12.710 \AA\right.$ and $11.673 \AA$, respectively). In the smallest cleft, bromide $(\mathrm{Br} 2)$ anion forms close contact with one of the triazine rings. The distance of bromide to the plane and to the centroid of triazinering is $3.429 \AA$ and $3.480 \AA$, respectively, reflecting a strong bromide- $\pi$ interaction. In the largest cleft, however, multiple and various noncovalent interactions are observed. The short distances depicted in Fig. 6, right, illustrate very clearly the bromide- $\pi$ and lpe- $\pi$ interactions between bromide and triazine and between water oxygen and triazine, respectively. The bromide and water in the cleft is hydrogen-bonded to each other $\left(d_{\mathrm{Br} 1-\mathrm{O} 4}=3.392 \AA\right)$ (Fig. 6, right). arene $\mathrm{C}-\mathrm{H}$ of one benzene moiety giving a $\mathrm{Cl}^{-\cdots} \mathrm{H}-\mathrm{C}$ distance of $3.541 \AA$. Moreover,

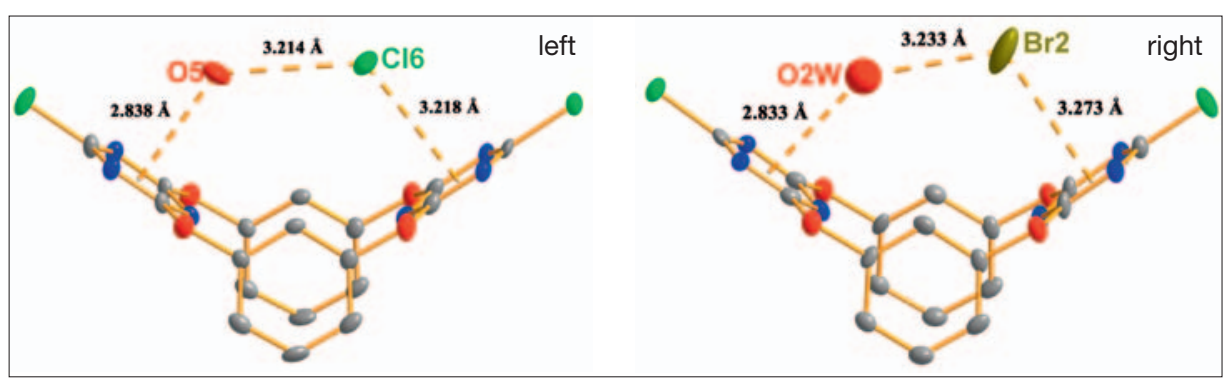

Fig. 5. X-ray single crystal structure of ternary complexes of $\mathbf{1}$ with halides and water.

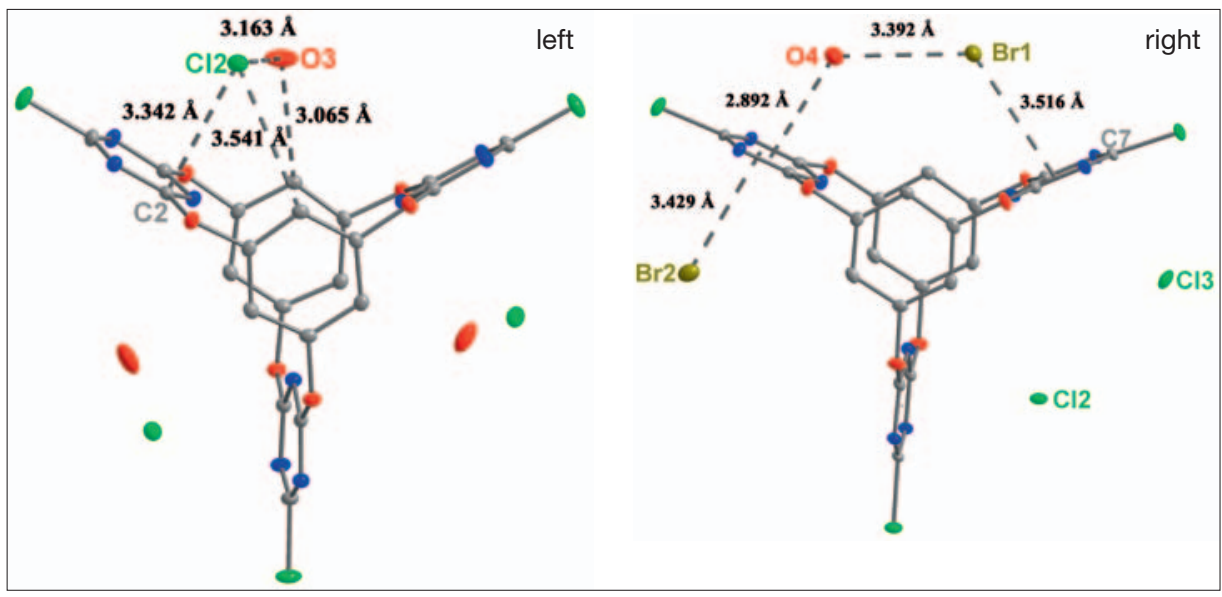

Fig. 6. Different types of anion- $\pi$ interactions observed in 4-chloride-water (left) and 4-bromidewater (right) complexes. 


\section{Anion- $\pi$ Interactions in Solution}

Anion- $\pi$ interaction is regarded as a weak interaction and the investigation in solution is challenging and remains largely unexplored. Recently, a few groups including ourselves have made progress in the study of anion- $\pi$ interactions in solution. ${ }^{[25,27-29,35-39]}$ By means of UV/ vis spectroscopic titration, Kochi and coworkers studied the interaction of halides and a number of aforementioned $\pi$-receptors. The observation of a new absorption band at $\lambda_{\text {max }} 400 \mathrm{~nm}$ was designated by authors to the charge transfer between anions and $\pi$ systems. The binding constants $\left(K_{\mathrm{CT}}\right)$ calculated are small, in the range of $1-10 \mathrm{M}^{-1}{ }^{[25]}$ Berryman and coworkers have designed several halide receptors and their associations with halides have been examined using ${ }^{1} \mathrm{H}$ NMR spectroscopic titrations. ${ }^{[35,36]}$ Molecule 5, for example, exhibits moderate binding with $\mathrm{F}^{-}, \mathrm{Cl}^{-}$ and $\mathrm{Br}^{-}$, giving association constants of $34 \mathrm{M}^{-1}, 20 \mathrm{M}^{-1}$ and $30 \mathrm{M}^{-1}$, respectively. As a control, molecule 6, which does not contain an electron-deficient aromatic moiety, shows no measurable binding to halides (Fig. 7). Taking advantage of the pre-organized conformational structure of calix [4]pyrrole, Ballester and coworkers ${ }^{[37]}$ have synthesized a variety of receptors 7 bearing different aromatic rings at the bridging positions (Fig. 7). The cavity, which is composed of four substituted benzene rings, is able to interact with an anion guest. On the basis of ${ }^{1} \mathrm{H}$ NMR spectroscopic study, authors have shown chloride- $\pi$ interactions in solution. The presence of a strong electron-withdrawing group on the benzene ring enhances the binding, and this has been exemplified by the change of binding constant $\mathrm{Ka}$ from $2.5 \times 10^{2} \mathrm{M}^{-1}$ for $7 \mathrm{a}$ to $1.8 \times 10^{5} \mathrm{M}^{-1}$ for 7d. Molecule 7f containing four paramethoxyphenyl groups shows the weakest interaction with an association constant of $1.3 \times 10^{2} \mathrm{M}^{-1}$ (Table 1 ). It should be pointed out that hydrogen binding between four pyrrole $\mathrm{N}-\mathrm{H}$ moieties and chloride plays a dominant role in recognizing anion guests. Dunbar and coworkers utilized UV/Vis titration, carbon and halogen NMR spectroscopy, and ESI-MS methods to investigate the charge transfer nature of the complex formed between halides and HAT(CN) ${ }_{6}{ }^{[27]}$ An interesting solventdependent binding phenomena has been noted by the authors. For example, in THF the binding constants of $3780 \mathrm{M}^{-1}$, $2200 \mathrm{M}^{-1}$ and $940 \mathrm{M}^{-1}$ are obtained for the complex of $\mathrm{HAT}(\mathrm{CN})_{6}$ with $\mathrm{Cl}^{-}, \mathrm{Br}^{-}$and $\mathrm{I}^{-}$, respectively. They decrease dramatically to $71 \mathrm{M}^{-1}, 48 \mathrm{M}^{-1}$ and $20 \mathrm{M}^{-1}$ in $\mathrm{CH}_{3} \mathrm{NO}_{2}$, respectively. Matile and coworkers have demonstrated in a recent study that anion- $\pi$ interaction is applicable to an

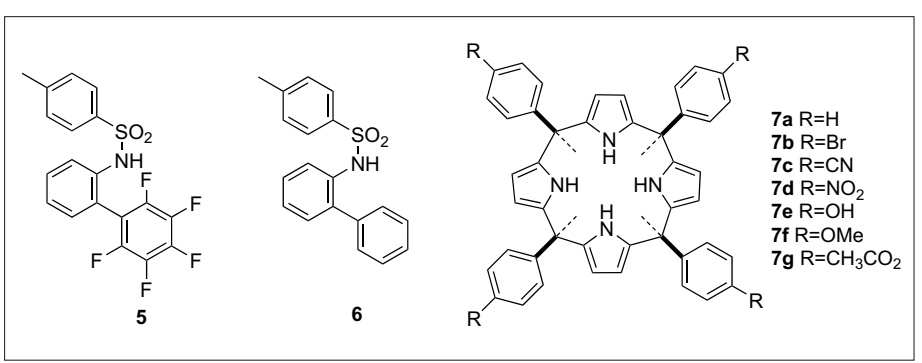

Fig. 7. The neutral receptors 5 and 6 by Berryman and coworkers for halide recognition and meso-tetraaryl calix[4] pyrrole receptors 7 for chloride recognition by Ballester and coworkers.

Table 1. Binding constants $K_{\mathrm{a}}\left(\mathrm{M}^{-1}\right)$ for the complexation between meso-tetraaryl calix[4] pyrrole receptors and chloride

\begin{tabular}{|l|c|}
\hline $\mathrm{R}$ & $\mathrm{Ka}\left(\mathrm{M}^{-1}\right)$ \\
\hline $\mathrm{H}$ & $2.5 \times 10^{2}$ \\
$\mathrm{Br}$ & $3.8 \times 10^{3}$ \\
$\mathrm{CN}$ & $3.3 \times 10^{4}$ \\
$\mathrm{NO}_{2}$ & $1.8 \times 10^{5}$ \\
$\mathrm{MeO}$ & $1.3 \times 10^{2}$ \\
$\mathrm{MeCO}_{2}$ & $1.1 \times 10^{3}$ \\
\hline
\end{tabular}

anion membrane transportation system employing naphthalenediimides (NDIs) as the $\pi$-deficient receptors. ${ }^{[38]}$ NDIs have also been used very recently by Saha and Guha as a fluoride sensing molecule based on the principle of anion- $\pi$ interactions. ${ }^{[39]}$

To shed light onto anion- $\pi$ interactions in solution phase, we investigated halide recognition with tetraoxacalix[2] arene[2]triazine hosts $\mathbf{1 - 3}$ by means of spectroscopic titrations and ${ }^{1} \mathrm{H}$ and ${ }^{19} \mathrm{~F}$ NMR spectroscopy. ${ }^{[28]}$ An interesting and remarkable substituent effect on the binding ability of electron deficient triazine ring has been observed. Based on the fluorescence titration study, for example, dichloro-substituted $\mathbf{1}$ forms complexes with fluoride and chloride in solution with binding constant $K_{a}$ around $4000 \mathrm{M}^{-1}$. On the contrary, tetraoxacalix[2] arene[2] triazine 3 with $N, N$-dimethylamino groups on the triazine rings shows no observable interaction with halides in solution (Table $2)$. It is most probably due to the electrondonating nature of the $N, N$-dimethylamino group which increases the electron density of triazine ring. Very recently, we have demonstrated that isothermal titration calorimetry (ITC) is a powerful method in the study of anion- $\pi$ interactions in solution. ${ }^{[29] \quad \text { All }}$ thermodyna mic parameters are obtained from the direct measurement of the net heat effect of the interaction between a cage molecule 4 and halides (Fig. 8, Table 3). ITC titration study indicates the formation of 1:1

${ }^{\mathrm{a}} T=298.15 \mathrm{~K}$
Table 2. Binding constants $K a(M-1)$ for the complexation between tetraoxacalix[2] arene[2]triazines 1-3 and halides

$\begin{array}{llll}\text { Host } & \mathrm{F}^{-} & \mathrm{Cl}^{-} & \mathrm{Br}^{-} \\ \mathbf{1} & 4036 \pm 36 & 4246 \pm 83 & -^{\mathrm{a}} \\ \mathbf{2} & 68 \pm 0 & --^{\mathrm{a}} & -^{\mathrm{a}} \\ \mathbf{3} & -^{\mathrm{a}} & --^{\mathrm{a}} & -^{\mathrm{a}}\end{array}$

${ }^{a}$ No observable spectral change

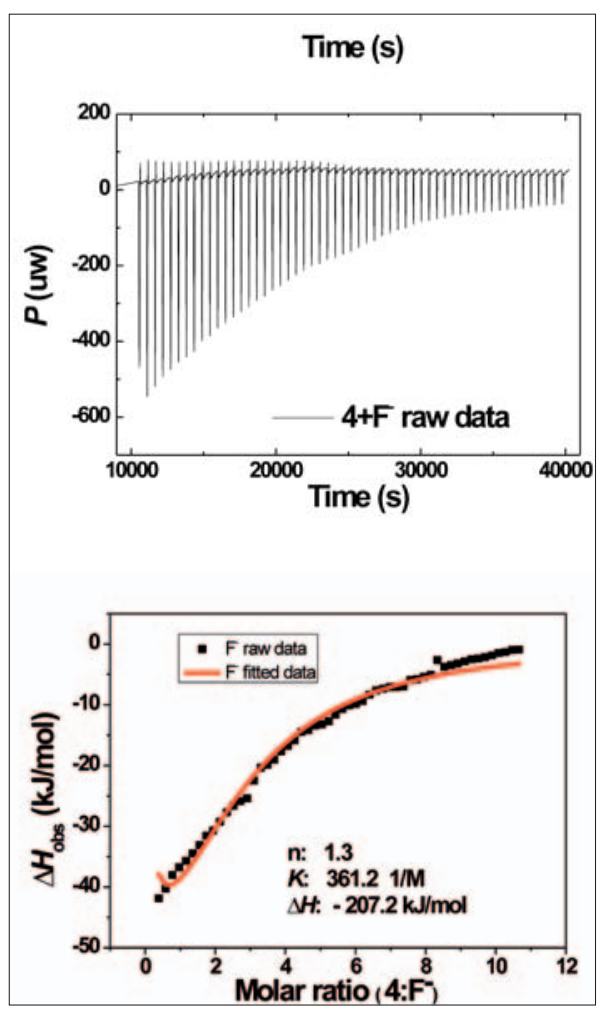

Fig. 8. The ITC titration of $\mathbf{4}$ with fluoride. top: raw data and bottom: fitted data.

complexes between $\mathbf{4}$ and halides, and the binding constant is in the order of fluoride (361 $\left.\mathrm{M}^{-1}\right)$, chloride $\left(146 \mathrm{M}^{-1}\right)$ and bromide

Table 3. Binding constants $\left(K_{2}\right)$ and thermodynamic parameters obtained by ITC titration for the 1:1 complex of 4 and halides

\begin{tabular}{|c|c|c|c|c|}
\hline Halides & $\begin{array}{c}\mathrm{K}_{\mathrm{a}} \\
\left(\mathrm{M}^{-1}\right)\end{array}$ & $\begin{array}{c}\mathrm{DG}^{\circ} \\
\left(\mathrm{kJ} \cdot \mathrm{mol}^{-1}\right)^{\mathrm{a}}\end{array}$ & $\begin{array}{c}\mathrm{DH}^{\circ} \\
\left(\mathrm{kJ} . \mathrm{mol}^{-1}\right)\end{array}$ & $\begin{array}{c}\Delta \mathrm{S}^{\circ} \\
\left(\mathrm{J} \cdot \mathrm{mol}^{-1} \cdot \mathrm{K}^{-1}\right)\end{array}$ \\
\hline $\mathrm{F}^{-}$ & 361 & -14.6 & -207.2 & -646.0 \\
\hline $\mathrm{Cl}^{-}$ & 146 & -12.3 & -11.0 & 4.4 \\
\hline $\mathrm{Br}^{-}$ & 95 & -11.3 & -6.6 & 15.8 \\
\hline
\end{tabular}




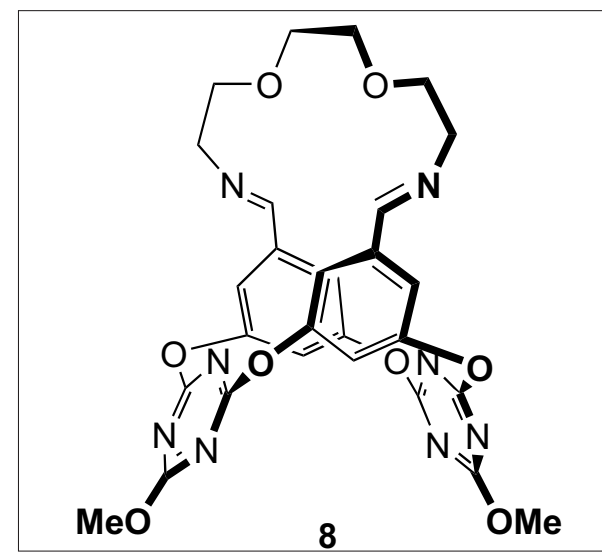

Fig. 9. Ditopic ion pair receptor 8.

$\left(95 \mathrm{M}^{-1}\right)$. The obtained enthalpy and entropy changes suggest the complexion of cage molecule $\mathbf{4}$ with halides is an enthalpy-driven process.

Anion- $\pi$ interactions have been applied very recently in the design of ditopic receptors for both zinc ion and fluoride anion recognition. ${ }^{[40]}$ The tetraoxacalixazacrown $\mathbf{8}$ is readily available from the condensation of a diamine and tetraoxacalix[2] arene[2]triazine functionalized with two aldehyde groups at the upper rim position (Fig. 9). The interaction with fluoride or zinc ion leads to the increase of the fluorescence intensity of $\mathbf{8}$ at $425 \mathrm{~nm}$ and 475 $\mathrm{nm}$, respectively. Titration of the $1: 1 \mathrm{com}-$ plex between 8 and zinc ion $\left([\mathbf{8} . \mathrm{Zn}]^{2+}\right)$ with fluoride results in great enhancement of intensity of the fluorescence band at $425 \mathrm{~nm}$ (Fig. 10). The more than 23-fold increase of the binding constant from $6.59 \times 10^{3} \mathrm{M}^{-1}$ $[8 . F]^{-}$to $1.53 \times 10^{5} \mathrm{M}^{-1}[\mathrm{Zn.8.F}]^{+}$indicates the ion pair recognition of $\mathbf{8}$ towards $\mathrm{Zn}^{2+}$ and $\mathrm{F}^{-}$. Furthermore, the $[\mathbf{8 . Z n}]^{2+}$ complex has been also found able to interact with chloride $\left(K a=7.39 \times 10^{3} \mathrm{M}^{-1}\right)$, bromide $\left(K a=1.59 \times 10^{3} \mathrm{M}^{-1}\right)$, and nitrate $(K a=$ $4.25 \times 10^{3} \mathrm{M}^{-1}$ ) species, which are not recognized by the parent host $\mathbf{8}$ alone.

\section{Conclusion}

As newly emerging supramolecular motifs, anion- $\pi$ interactions with charge neutral electron-deficient organic host molecules have attracted substantial interest in very recent years. While theoretical and experimental studies will lead to deeper insight into the nature of anion- $\pi$ interactions, applications of anion- $\pi$ interactions in selective anion recognition and sensing, anion-directed molecular self-assembly and fabrication of functional materials are anticipated in the years to come. Furthermore, the function and mechanism of anion- $\pi$ interactions in biological systems remain largely unknown ${ }^{[24]}$ and study in this field is worth the endeavor.

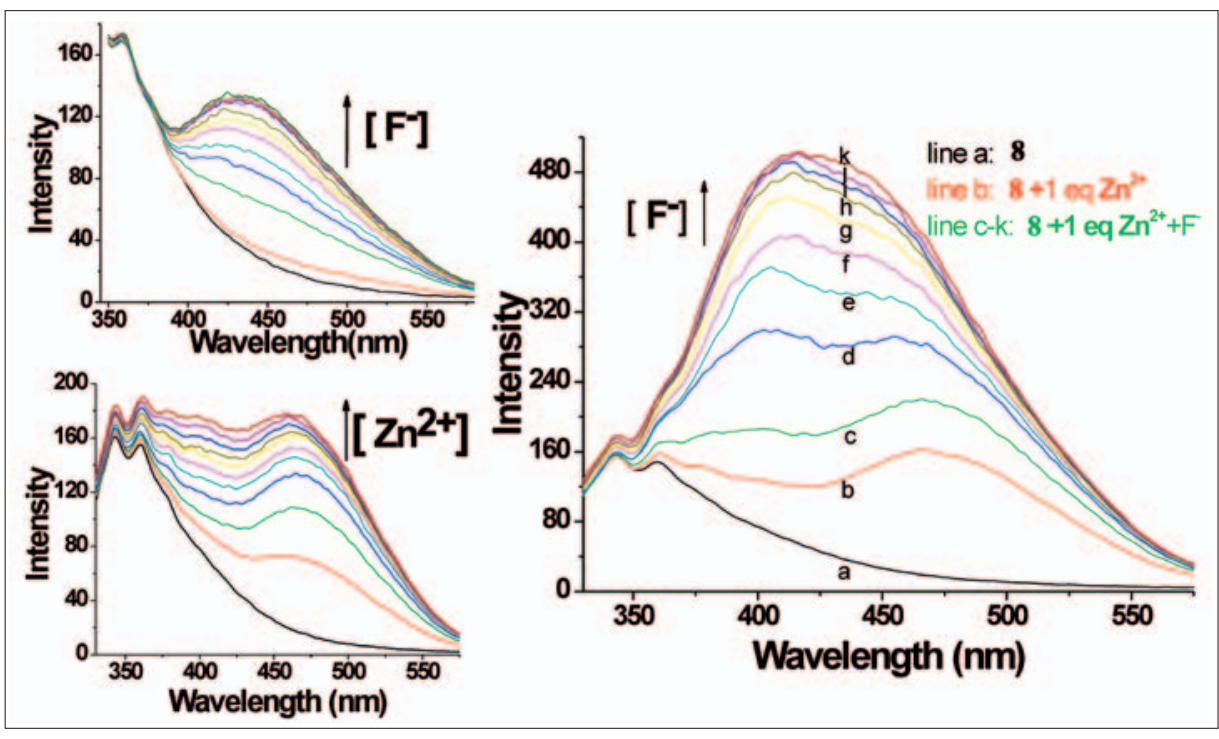

Fig. 10. Left: Fluorescence titration of 8 with $\mathrm{F}^{-}$(top) and $\mathrm{Zn}^{2+}$ (bottom). Right: Fluorescence titration of $\mathbf{8}$ with $\mathrm{F}^{-}$in the presence of one equivalent of $\mathrm{Zn}^{2+}$.

\section{Acknowledgement}

We thank National Natural Science Foundation of China (20875094, 21072197, 20972161, 21121004, 21132005), Ministry of Sciences and Technology (2011CB932501, 2007CB808005) Chinese Academy of Sciences and Tsinghua University for financial support.

Received: October 16, 2011

[1] J. W. Steed, J. L. Atwood, 'Supramolecular Chemistry', John Wiley and Sons, Ltd., 2009.

[2] 'Anion Sensing in Topics in Current Chemistry', Eds. A. de Meijere, K. N. Houk, H. Kessler, J. -M. Lehn, S. V. Ley, S. L. Schreiber, J. Thiem, B. M. Trost, F. Vogtle, H. Yamamoto, SpringerVerlag Berlin Heidelberg, 2005.

[3] F. P. Schmidtchen, Angew. Chem. Int. Ed. Engl. 1977, 16, 720.

[4] P. A. Gale, J. L. Sessler, V. Král, V. Lynch, J. Am. Chem. Soc. 1996, 118, 5140.

[5] X. Yang, C. B. Knobler, M. F. Hawthorne, Angew. Chem., Int. Ed. 1991, 30, 1507.

[6] M. Mascal, A. Armstrong, M. D. Bartberger, J. Am. Chem. Soc. 2002, 124, 6274.

[7] D. Quiñonero, C. Garau, C. Rotger, A. Frontera, P. Ballester, A. Costa, P. M. Deyà, Angew. Chem., Int. Ed. 2002, 41, 3389.

[8] I. Alkorta, I. Rozas, J. Elgueo, J. Am. Chem. Soc. 2002, 124, 8593 .

[9] P. Gamez, T. J. Mooibroek, S. J. Teat, J. Reedijk, Acc. Chem. Res. 2007, 40, 435.

[10] B. L. Schottel, H. T. Chifotides, K. R. Dunbar, Chem. Soc. Rev. 2008, 37, 68.

[11] A. Robertazzi, F. Krull, E.-W. Knapp, P. Gamez, CrystEngComm, 2011, 13, 3293.

[12] I. Alkorta, I. Rozas, J. Elguero, J. Org. Chem. 1997, 62, 4687

[13] J. P. Gallivan, D. A. Dougherty, Org. Lett. 1999, $1,103$.

[14] D. Kim, P. Tarakeshwar, K. S. Kim, J. Phys. Chem. A. 2004, 108, 1250.

[15] O. B. Berryman, V. S. Bryantsev, D. P. Stay, D. W. Johnson, B. P. Hay, J. Am. Chem. Soc. 2007, $129,48$.

[16] C. Garau, A. Frontera, D. Quiñonero, P. Ballester, A. Costa, P. M. Deyà, Chem. Phys. Lett. 2003, 382, 534.

[17] C. Garau, D. Quiñonero, A. Frontera, A. Costa, P. Ballester, P. M. Deyà, Chem. Phys. Lett. 2003, 370, 7 .

[18] A. Frontera, F. Saczewski, M. Gdaniec, E. Dziemidowicz-Borys, A. Kurland, P. M. Deyà,
D. Quiñonero, C. Garau, Chem.-Eur. J. 2005, 11,6560 .

[19] C. Garau, D. Quiñonero, A. Frontera, P Ballester, A. Costa, P. M. Deyà, J. Phys. Chem. A 2005, 109, 9341

[20] M. Mascal, Angew. Chem., Int. Ed. 2006, 45, 2890.

[21] D. Y. Kim, N. J. Singh, K. S. Kim, J. Chem Theory Comput. 2008, 4, 1401.

[22] C. Estarellas, M. C. Rotger, M. Capo, D. Quiñonero, A. Frontera, A. Costa, P. M. Deyà, Org. Lett. 2009, 11, 1987.

[23] M. E. Alberto, G. Mazzone, N. Russo, E. Sicilia, Chem. Commun. 2010, 46, 5894.

[24] C. Estarellas, A. Frontera, D. Quiñonero, P. M Deyà, Angew. Chem., Int. Ed. 2010, 50, 415.

[25] Y. S. Rosokha, S. V. Lindeman, S. V. Rosokha, J. K. Kochi, Angew. Chem., Int. Ed. 2004, 43 , 4650.

[26] B. Han, J. Lu, J. K. Kochi, Cryst. Growth Des. 2008, 8, 1327.

[27] H. T. Chifotides, B. L. Schottel, K. R. Dunbar, Angew. Chem., Int. Ed. 2010, 49, 7202.

[28] D.-X. Wang, Q.-Y. Zheng, Q.-Q. Wang, M.-X Wang, Angew. Chem., Int. Ed. 2008, 47, 7485.

[29] D.-X. Wang, Q.-Q. Wang, Y. Han, Y. Wang, Z. T. Huang, M.-X. Wang, Chem. Eur. J. 2010, 16, 13053.

[30] M.-X. Wang, Chem. Commun. 2008, 4541.

[31] W. Maes, W. Dehaen, Chem. Soc. Rev. 2008, 37, 2393.

[32] H. Tsue, K. Ishibashi, R. Tamura, Top. Heterocycl. Chem. 2008, 17, 73.

[33] M.-X. Wang, Acc. Chem. Res. 2011, 10.1021/ ar200108c

[34] M.-X. Wang, H.-B. Yang, J. Am. Chem. Soc. 2004, 126, 15412.

[35] O. B. Berryman, M. J. Hynes, D. W. Johnson, Chem. Commun. 2006, 506.

[36] O. B. Berryman, A. C. Sather, B. P. Hay, J. S. Meisner, D. W. Johnson, J. Am. Chem. Soc. 2008, 130, 10895

[37] G. Gil-Ramirez, E. C. Escudero-Adan, J. BenetBuchholz, P. Ballester, Angew. Chem., Int. Ed. 2008, 47, 4114.

[38] R. E. Dawson, A. Hennig, D. P. Weimann, D. Emery, V. Ravikumar, J. Montenegro, T. Takeuchi, S. Gabutti, M. Mayor, J. Mareda, C. A. Schalley, S. Matile, Nature Chem. 2010, 2, 533.

[39] S. Guha, S. Saha, J. Am. Chem. Soc. 2010, 132, 17674.

[40] Y. Chen, D.-X. Wang, Z.-T. Huang, M.-X. Wang, Chem. Commun. 2011, 47, 8112. 